engage in activities that expose them to risk. Because HIV infection rates have stabilised, there is evidence of reduced HIV morbidity and mortality as a result of advances in treatments, and a climate of greater optimism has arisen. Yet there is significant uncertainty about the long-term effects of new treatments. As the epidemic is changing, so too is the way HIV is perceived and understood by affected communities, the broader community and by government. These changes have the potential to undermine the community's capacity to sustain an effective response to HIV and AIDS.

Currently, rates of gonorrhea and of other sexually transmissible infections that may enhance HIV transmission are rising, both here in Australia and overseas. There is a need to explore new measures for encouraging safe sex behaviours in order to enhance the control of HIV and other sexually transmissible infections.
While much has been achieved in NSW, much remains to be done in pursuing reforms and ensuring appropriate responses to the changing epidemic. This includes a willingness to trial new interventions, develop clear communication strategies and address the tensions between strategies for harm reduction and those for use reduction for drug use.

\section{REFERENCES}

1. National Centre in HIV Epidemiology and Clinical Research. $H I V-A I D S$, viral hepatitis, and sexually transmissible infections in Australia Annual Surveillance. Sydney: NCHECR, 2002.

2. AIDS Council of NSW. Strengthening the Community ACON and the HIV epidemic in NSW. Sydney: ACON, 1995.

3. Australian National Council on AIDS and Related Diseases. Protecting our Investment. 1997 Report to the Minister for Health and Family Services. Canberra: ANCARD,1998.

\title{
MAY 1999 NSW DRUG SUMMIT
}

Rafe Champion and Jennifer Gray

Drug Programs Bureau

NSW Department of Health

In late 1998 there was a widespread perception that the problem of illicit drugs was not being adequately addressed through existing resources and policies. The Premier of New South Wales made the commitment that, if re-elected in the March 1999 election, there would be a summit on the drug problem. This article describes that drug summit, the purpose of which was to make a fresh start and achieve bipartisan agreement on major strategies to address illicit drugs.

The NSW Drug Summit was held in May 1999. All NSW state government politicians were invited, as were approximately 100 members of the public who were selected to represent the widest possible range of expertise and experience. The agenda of the summit covered many aspects of the illicit drug problem including: education, prevention, treatment, young people, regional and rural NSW, and the role of the police and the criminal justice system. Ministers and experts facilitated group discussions that reported back to plenary sessions. In these plenary sessions, resolutions were put to a vote, which resulted in a consensus on 20 general principles and 172 resolutions that covered a wide range of issues.

These resolutions formed the framework of the NSW Government Plan of Action on drugs, ${ }^{1}$ and was supported with a financial commitment of $\$ 176$ million over four years.

\section{THE STATEWIDE DRUG TREATMENT SERVICES PLAN}

For NSW Health, the first step was the development of a statewide Drug Treatment Services Plan to guide subsequent initiatives. This was a major opportunity to rethink the delivery of services. The central themes of the plan are access, quality and integrated care.

\section{Access}

A geographical imbalance of treatment services existed, with most resources concentrated in the metropolitan areas. Drug treatment services were overstretched, especially the methadone program. Following the Drug Summit, many projects specifically targeted rural and regional communities. These include:

- The appointment of drug and alcohol counsellors and drug and alcohol nurses in each of the rural area health services;

- Multi-purpose drug and alcohol facilities established in the Mid North Coast and New England Area Health Services;

- A newly-constructed inpatient detoxification service at Lismore, to complement new detoxification services situated at Wyong and Penrith;

- The General Practitioner (GP) Program, designed to increase the ability of GPs both to recognise problems arising from drug misuse by their patients and to respond appropriately. The program has been extended from 11 to 17 area health services. 


\section{FIGURE 1}

THE AVAILABILITY OF METHADONE AND BUPRENORPHINE TREATMENT (MBT), NSW, JANUARY 1999 TO MARCH 2002

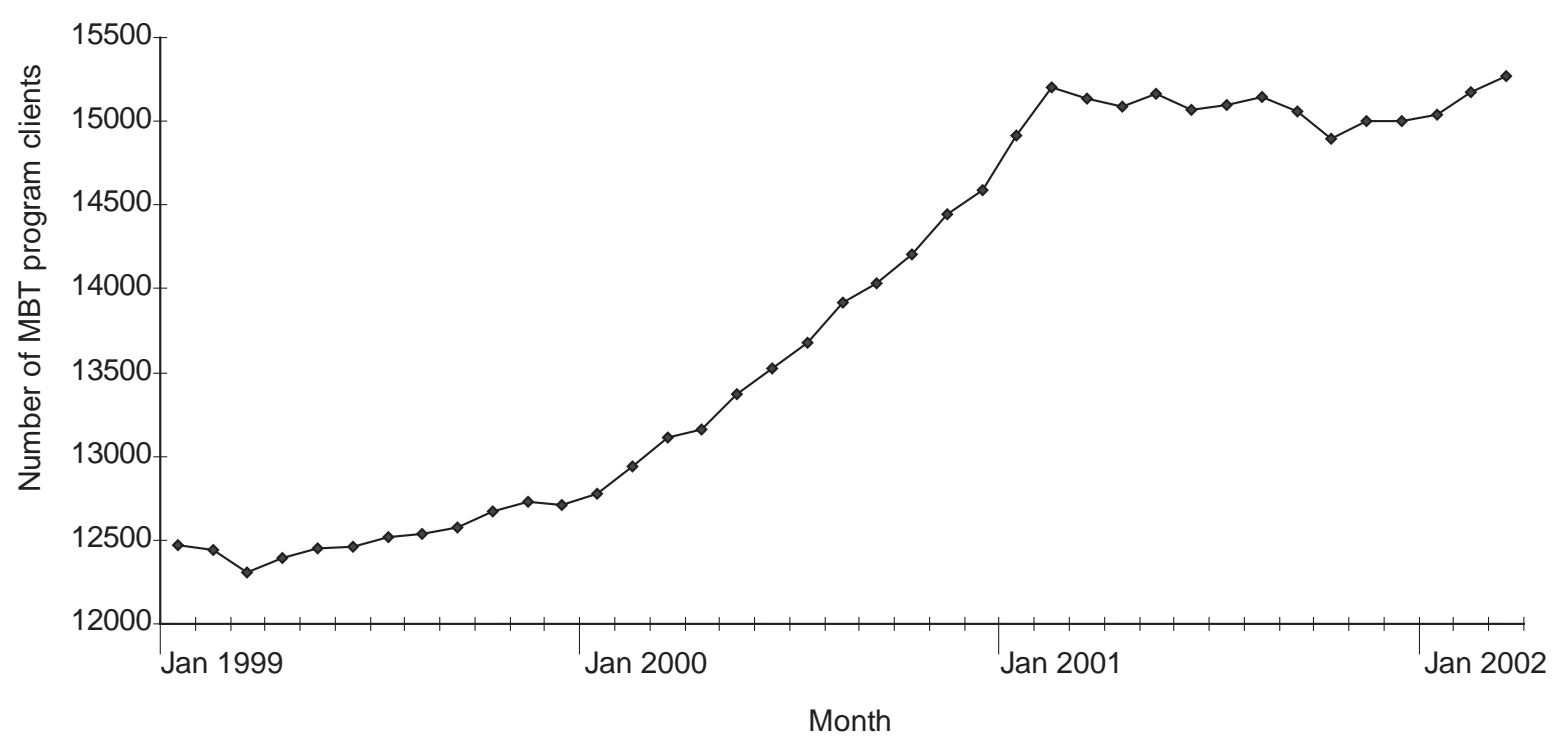

Sources: Patient numbers-Pharmaceutical Services Branch Database.

\section{Quality}

There are many initiatives to improve the quality of drug treatment services, both public and private. The full suite of initiatives include: the introduction of treatment agreements and treatment plans; the accreditation of services; improved training for methadone prescribers; the monitoring of quality, including the prescription of takeaway doses of methadone; and a more proactive stance by the Pharmacotherapy Credentialling Subcommittee. These quality initiatives represent the first step towards a paradigm shift in the culture of treatment and rehabilitation for drug-dependent patients.

\section{Integrated care}

The NSW Government Plan of Action on drugs has created many challenges, as structures and procedures are put in place to ensure coordination between agencies, and to provide continuity of care, as patients move between agencies to obtain the full range of services that they require.

Partnerships with non-Government agencies are a highlight of the Plan. Funding has been provided to the Network of Alcohol and Drug Agencies, and to individual agencies, to enhance their information technology. Agencies are being encouraged to relate more closely to the area health services in which they are located, in order to improve the coordination and continuity of care of their patients.

Diversion of drug-users form the criminal justice system into treatment is an important area where NSW Health works, with the assistance of Commonwealth funding, with other agencies and the non-government sector. Programs such as the Magistrate's Early Referral Into Treatment now provide drug users with the option of treatment rather than a jail term, in order to break the cycle of criminal recidivism that can be related to drug abuse.

\section{NEEDS OF SPECIAL GROUPS}

Programs are being implemented to provide support for drug-dependent carers with children. One of these programs is Parents Under Pressure, which is an intensive program delivered at home to build skills and confidence in parenting and other domestic competencies.

\section{OUTCOMES}

Since 1999, there has been a reduction in heroin-related overdose events (defined as deaths and non-fatal incidents) from 400 in 1999 to 249 in $2000 .^{2}$ This represents a 38 per cent decline in NSW, which compares favourably with the 24 per cent decline nationally. It should be noted that this decline preceded the recent heroin shortage. Figures 1 and 2 illustrate the inverse relationship between the availability of methadone and buprenorphine treatment and the number of suspected opiate overdose deaths from early 1999 to March 2002. ${ }^{3}$

Access to pharmacotherapy treatment (methadone and buprenorphine) has improved significantly and there are now few parts of the state where there is a significant 
FIGURE 2

THE NUMBER OF SUSPECTED OPIATE OVERDOSE DEATHS IN NSW FROM EARLY 1999 TO MARCH 2002

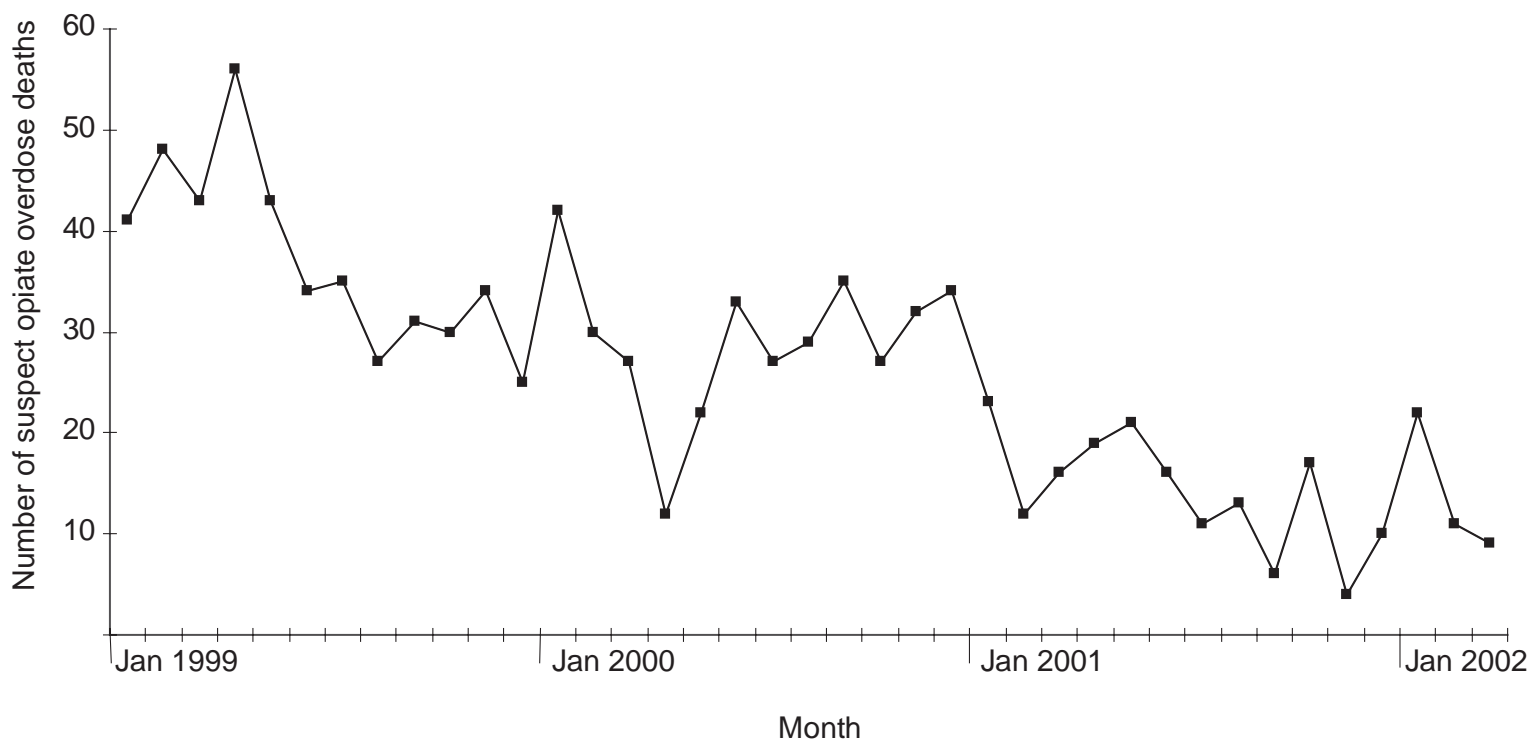

Sources: Overdose figures-Division of Analytical Laboratories.

delay for patients wishing to enter treatment. The successful introduction of buprenorphine as an alternative pharmacotherapy for the treatment of heroin addiction has attracted many new patients to treatment and provides more flexibility in the delivery of care.

The pressure on rehabilitation beds in the non-government sector has been reduced with funding allocated for 62 additional beds. In addition, some agencies have undertaken to modify their service configuration to provide more beds than they receive funding for.

\section{CONCLUSIONS AND CHALLENGES}

The major outcome of the NSW Drug Summit, and the 150 projects administered by the Drug Programs Bureau, has been a significant increase in the number of drugdependent patients who are being managed in the health system, and a significant increase in services provided by agencies in partnership with NSW Health.

Inevitably, there are persisting challenges in making major changes in a very large and complex system. The rapid expansion of services has created shortages of adequately trained and experienced staff. The complexity of the treatment system, and the nature of opioid dependence, creates problems both for monitoring the effectiveness of interventions and maintaining gains. Treatment systems need to be flexible in order to be able to respond to changes in patterns of drug use. However, flexibility can be difficult to achieve, with so many independent agencies involved in the planning and delivery of the services.
In addition, alcohol misuse remains a major community concern, and this issue was not a focus of the NSW Drug Summit.

The NSW Department of Health had responsibility for a large proportion of the additional funding and new projects which followed the Drug Summit and the Government Plan of Action. Within the Department, the Drug Programs Bureau was the coordinating branch.

The Drug Programs Bureau website has a list of state, national, and international links.

http://internal.health.nsw.gov.aulpublichealthldpb/contact.htm.

The website for the NSW Drug Summit can be found at www.druginfo.nsw.gov.au/druginfo/ summit/index.html.

\section{REFERENCES}

1. NSW Government. NSW Drug Summit 1999: Government Plan of Action. Sydney: NSW Government, July 1999.

2. National Drug and Alcohol Research Centre. Australian Bureau of Statistics data on opioid overdose deaths. Sydney: NDARC, 2000.

3. Degenhart L. Opioid Overdose Deaths in Australia: Sydney: NDARC, 2001. 